\section{Uso do sensoriamento remoto para estudar a influência de alterações ambientais na distribuição da malária na Amazônia brasileira}

\author{
Use of remote sensing to study the influence \\ of environmental changes on malaria distribution \\ in the Brazilian Amazon
}

Cíntia Honório Vasconcelos 1

Evlyn Márcia Leão de Moraes Novo ${ }^{2}$ Maria Rita Donalisio 3

\section{Introdução}

\section{O desmatamento na Amazônia}

Construction of the Tucuruí hydroelectric dam
in Southeast Pará State, Brazil, in 1981, caused enormous environmental changes, deforestation, and human migration to the region. This study focuses on the influence of these changes and the appearance of malaria in the municipality of Jacundá, Pará, using remote sensing and geographic information systems. The variables used to construct maps were distances from roads, farming areas, rivers, the dam, streams, and the urban area. This study confirmed the elevation of malaria to the epidemic level since the construction of the Tucurui dam. The study suggests that a seasonal pattern of malaria incidence is associated with the flooding season and exposure of workers during harvest. Malaria cases were related to the form of land occupation, especially in more densely populated areas.

Malaria; Hydroelectric Power Plant; Environmental Change; Remote Sensors
A Bacia Amazônica ocupa uma área de aproximadamente $6.600 .000 \mathrm{~km}^{2}$ pertencente ao Brasil, Colômbia, Equador, Peru, Bolívia e Venezuela. Apesar de o desmatamento estar ocorrendo em todos os países da Amazônia, no Brasil ele é mais intenso; além disso, é o único país que fornece dados mais precisos sobre alterações da cobertura da terra nessa região. As estimativas anuais de desmatamento são geradas pelo Instituto de Pesquisas Espaciais (INPE), utilizando imagens de satélite que verificou no período de dez anos, entre 1988 e 1998, que a área desmatada foi de $174.000 \mathrm{~km}^{2}$ com média de desmatamento na Amazônia brasileira de $15.000 \mathrm{~km}^{2}$ por ano, sendo que no período de $1994 / 1995$ este número saltou para $29.000 \mathrm{~km}^{2}$. As principais áreas desmatadas coincidiram com a fronteira agrícola que avança em direção ao norte dos Estados do Pará, Tocantins, Mato Grosso, Rondônia e Acre 1.

Além da perda de áreas de floresta pelo desmatamento para abertura de estradas, construção de hidroelétricas, agricultura e pastagens há o problema de incêndios. As florestas densas são naturalmente mais resistentes ao fogo, pois possuem vegetação de grande porte que retém maior umidade, enquanto áreas alteradas são menos resistentes. Imagens obtidas por 
satélites mostram que a maior incidência de fogo na Amazônia se concentra nas proximidades das estradas e de áreas também próximas às habitações humanas 2 .

A fumaça produzida pelos incêndios irá saturar a atmosfera, mas a água das nuvens não será pesada o suficiente para cair na terra. Conseqüentemente, existe uma retroalimentação positiva entre desmatamento, fogo e fumaça, causando a redução das chuvas e da umidade retida na vegetação e no solo ${ }^{3}$. A evapotranspiração da floresta é umas das mais importantes fontes de vapor de água, cuja redução drástica acarretaria na diminuição da precipitação e possível aumento da temperatura regional 4 . O clima da Amazônia está interligado com a floresta que produz vapor d'água para a atmosfera, absorve energia solar que aquece parcelas da umidade do ar que formará nuvens 5 .

O desmatamento tem várias causas. Primeiro é o aumento de populações não-indígenas desde 1960, a partir de quando entre 2 e 20 milhões de pessoas migraram para a região; segundo é o crescimento da indústria madeireira e mineradora, além do aumento da malha viária que permite maior acesso de fazendeiros e colonizadores; terceiro, avanço do desmatamento para o interior da bacia, o qual antes se concentrava nas partes leste e sudeste, mas agora as estradas, projetos madeireiros e de colonização penetram no coração da Bacia Amazônica; e finalmente, os incêndios provocados pela própria população no manejo das pastagens e de áreas para cultivo 6 .

Embora a redução da umidade relativa seja um fator que iniba a proliferação dos vetores, existe grande disponibilidade de água (margens de rios, represas). Assim, a elevação da temperatura pode proporcionar uma explosão de mosquitos vetores de doenças. A malária é endêmica na Amazônia e seus vetores possuem ecologias muito diversificadas e com grande capacidade de adaptação ao meio.

Essas mudanças ambientais contribuem para a substituição das florestas tropicais por áreas degradadas, favorecendo a migração/ adaptação de vetores, reservatórios em regiões endêmicas e observando-se a emergência de doenças ou sua expansão para novos ecótopos 7,8.

\section{A migração como fator agravante para o controle da malária}

Quanto aos ocupantes das terras na Amazônia, tem sido observado que propriedades vizinhas possuem padrões de uso da terra completamente diferentes. Isso se deve a variações do capital inicial das famílias migrantes, de suas origens e de suas experiências com a agricultura e com a região 9 .

Propriedades com maior disponibilidade de mão-de-obra geralmente tornam-se envolvidas no cultivo de culturas perenes como árvores frutíferas, café, cacau e pimenta-do-reino. Por outro lado, as propriedades mantidas com a mão-de-obra de pequenas famílias enfocam suas atividades na criação de gado e culturas anuais. Durante o trabalho de campo esses trabalhadores são as principais vítimas da malária porque entram em contato direto com o vetor. O pasto sujo com vegetação que pode servir de abrigo aos mosquitos adultos, faz com que esses trabalhadores sejam fontes de alimento em potencial. Outro problema é que na maioria das vezes, as suas habitações não possuem a menor infra-estrutura e se localizam nas partes mais baixas do terreno, próximas aos igarapés 9 .

No período de 1970/1980, a população urbana da Amazônia passou de $37,7 \%$ para $51,8 \%$ devido os incentivos do governo com a implantação de grandes projetos (mineradores, agrícolas, hidroelétricos) 10.

O deslocamento interno de pessoas entre regiões da Amazônia e entre outras regiões do país causou a migração da malária para essas áreas. No Pará, por exemplo, foi constatado que na rodovia Cuiabá-Santarém muitos indivíduos infectados eram procedentes de garimpos do norte do Mato Grosso 11. Segundo esses mesmos autores, os movimentos migratórios são os principais responsáveis pela dificuldade de controlar a malária na Amazônia. O grande número de casos e a grande dispersão regional não permitiam que os doentes fossem tratados em tempo hábil.

A malária está ligada principalmente às mudanças ambientais 12 . O desmatamento agregado ao fluxo migratório de pessoas que passam a ter contato direto com os vetores acarreta epidemias sem que os órgãos de saúde consigam controlar 11. De um modo geral, essa população migrante vive em condições precárias de habitação, nutrição e de saúde, o que favorece a transmissão e dificulta seu controle. Outro motivo que agrava a situação da malária na Amazônia é a grande quantidade de pessoas suscetíveis à infecção por não possuírem resistência adquirida contra a doença, pois são procedentes de áreas onde a malária não existe há muitos anos 13

Embora na região Amazônica tenha-se registro de sucessivos planos para enfrentar a malária desde a década de 60 , apenas nos últimos anos houve notificação de redução da incidência e da mortalidade por malária, a partir 
do maior envolvimento dos municípios no diagnóstico, tratamento e investigação dos casos. A partir de 2000, registra-se a redução de $39 \%$ de casos nos estados amazônicos com a queda de $35 \%$ da infecção pelo Plasmodium falciparum e $41 \%$ do Plasmodium vivax. Embora estes indicadores globais sejam favoráveis, a malária tem ocorrido de forma heterogênea nas centenas de municípios da região 14 . Enquanto observam-se áreas hipoendêmicas na Amazônia, com relativa estabilidade da transmissão, notifica-se epidemias em regiões de ocupação recente 15. Este é o caso da região vizinha a Balbina e Tucuruí no Pará.

Um dos principais impactos ambientais causados pelo plano de desenvolvimento da Amazônia foi a construção de grandes hidroelétricas como Balbina e Tucuruí. Além das profundas mudanças na urbanização e ocupação do espaço da região, as represas influenciam na qualidade da água, principalmente em áreas de floresta devido à decomposição de biomassa. A liberação de nutrientes causa a eutrofização, resultando no crescimento de macrófitas, vegetação aquática que são bons criadouros de mosquitos 16 .

Como a malária é uma doença complexa que está relacionada com a interação entre o parasita, o vetor, os hospedeiros humanos e o meio ambiente é imprescindível o estudo em conjunto de todos esses fatores para se tentar controlá-la. A combinação de fatores humanos com informações ambientais relevantes à biologia da doença pode permitir enxergar melhor uma situação epidemiológica de risco, facilitando a ação dos serviços de saúde 17. Imagens de satélites estão sendo usadas por epidemiologistas para o estudo em conjunto desses diversos fatores que estão relacionados à disseminação de doenças. $\mathrm{O}$ sensoriamento remoto integrado a um sistema de informação geográfica contribui para trazer a ecologia das paisagens para uma dimensão analítica. Tais recursos já permitiram a análise de ocorrência de várias doenças, cuja transmissão se relaciona com mudanças ambientais e na interação do homem com a natureza 18,19,20.

Tendo em vista que o risco de contrair malária está relacionado a alterações ambientais causadas por atividades humanas, este trabalho tem como objetivo verificar a influência dessas mudanças na ocorrência da malária no Município de Jacundá, utilizando técnicas de sensoriamento remoto e sistemas de informações geográficas.

\section{Materiais e métodos}

\section{Área de estudo}

A formação do lago de Tucuruí a partir de 1980 atingiu nove municípios, dentre os quais o $\mathrm{Mu}$ nicípio de Jacundá inserido no sudeste paraense. Esse município está situado na margem direita do reservatório de Tucuruí a uma altitude de $84 \mathrm{~m}$, com população total de aproximadamente 39.420 habitantes e densidade demográfica de 19,57 habitantes $/ \mathrm{km}^{2}$.

As principais atividades no Município de Jacundá são a pecuária, com 50 mil cabeças de gado, e a agricultura com o cultivo de lavouras temporárias como a do arroz (3.000ha), milho (1.600ha), mandioca (1.500ha), feijão (40ha) e culturas permanentes como banana, pimentado-reino, laranja etc. A extração da madeira é realizada cada vez mais distante das áreas de serraria (próximas à Cidade de Jacundá), pois esse município já desmatou quase totalmente suas áreas de floresta (Instituto Brasileiro de Geografia e Estatística. Cidades. http:/ / www. ibge.gov.br, acessado em 15/Jan/2004).

\section{Materiais e equipamentos}

Para a realização da pesquisa foram utilizados dados extraídos da bibliografia consultada; imagens do sensor TM-Landsat 5 para os anos de $1996 \mathrm{e}$ 2001, em formato digital; folhas topográficas do Instituto Brasileiro de Geografia e Estatística (IBGE) na escala de 1:100.000; foram utilizados números de casos positivos de malária, agregados por município, para o período de 1962/2002; e os índices parasitários anuais (IPA), de 1992/2001, por localidade, cedidos pela Fundação Nacional de Saúde (FUNASA) do Estado do Pará.

Os dados de precipitação foram cedidos pela Agência Nacional de Águas (ANA) e os dados de vazão e cota do reservatório, cedidos pelas Centrais Elétricas da Região Norte (ELETRONORTE).

O programa Spring 3.6 (Sistema de Processamento de Informações Georreferenciadas), desenvolvido no INPE, permitiu integrar os dados de sensoriamento remoto com os dados de malária.

Foi realizado trabalho de campo para georreferenciar as localidades de ocorrência de malária, segundo a FUNASA.

Os anos de 1996 e 2001 foram escolhidos para este estudo porque estavam disponíveis dados de malária por localidade num lapso de tempo que permitisse acompanhar a dinâmica de alteração do uso da terra e seu impacto sobre a dispersão da doença. 
Processamento digital das imagens orbitais TM - Landsat 5

A primeira etapa do trabalho foi a extração e transformação da base cartográfica (estradas e drenagem) na escala de 1:100.000 para formato digital. As folhas topográficas foram obtidas no formato digital e importadas para o programa Spring 3.6, registradas e só depois digitalizadas. $\mathrm{O}$ registro das imagens TM-Landsat em formato digital foi realizado de duas formas: imagembase cartográfica e imagem-imagem. A função do registro é corrigir as imagens de sensoriamento remoto segundo algum sistema de coordenadas para terem precisão cartográfica 21 .

Outra importante etapa do trabalho foi a aplicação do modelo linear de mistura espectral 22 nas bandas originais 3, 4 e 5 TM-Landsat para gerar as três componentes referentes à vegetação, ao solo e à sombra. O algoritmo do modelo linear de mistura espectral permite separar as contribuições espectrais de cada objeto dentro de um pixel, no caso foram separados vegetação, solo e sombra que também corresponde à água. O passo seguinte foi aplicar o algoritmo de segmentação de imagens (crescimento de regiões). Neste processo a imagem é subdividida em regiões, tendo como base propriedades dos pixels como níveis de cinza e textura 23 . Em seguida foi realizada a classificação supervisionada distância Bhattacharya 24 , com o intuito de obter os mapas de uso e ocupação da terra do Município de Jacundá para os anos de 1996 e 2001. As classes selecionadas para este mapeamento foram: vegetação nativa não antropizada, vegetação em regeneração, corte seletivo, atividades agrossilvopastoris (áreas agrícolas, pastagens e solo exposto), área urbana, área alagada, água, banco de areia e nuvem. Essa metodologia encontra-se descrita em Vasconcelos \& Novo 25.

\section{Mapas de distribuição da população e de risco de malária}

Um dos motivos para se gerar mapas de distribuição da população foi a necessidade de se obter dados para o município inteiro e não apenas para as localidades georreferenciadas no campo, uma vez que um dos objetivos do trabalho é modelar áreas susceptíveis à malária para toda a área de estudo.

O método utilizado para gerar os mapas de distribuição da população e de risco de malária para o município estudado foi o de álgebra de mapas 26,27 , que permite o cruzamento de mapas.

As variáveis utilizadas para obter esses mapas foram extraídas das imagens de satélite e de observações de campo, considerando-se variáveis epidemiológicas relevantes na transmissão da doença 12,15. As variáveis estipuladas para o mapa de distribuição da população foram: distância da classe agrossilvopastoril; distância das estradas e dos cruzamentos de estradas; distância dos igarapés, rios e do reservatório; distância da área urbana. Procedimentos semelhantes foram utilizados para gerar superfícies de densidade populacional para o Município de Marabá, Pará 28. Seus estudos demonstraram que as estimativas de população podem ser obtidas indiretamente com base em medidas da extensão da superfície urbanizada medida sobre imagens ou pela classificação do uso e ocupação da terra. Os testes de técnicas de inferência fuzzi realizados nesse trabalho indicaram que as melhores estimativas foram obtidas com o uso de média simples das seguintes variáveis: distância das vias, distância de rios, distância de núcleos urbanos, porcentagem de floresta e declividade.

Para a obtenção dos mapas de risco foram consideradas as variáveis: os mapas de distribuição da população; distância dos igarapés, rios e do reservatório; distância das estradas; distância das áreas de macrófitas; uso do solo; distância da área urbana.

A malária está relacionada à população $\mathrm{e}$ por isso foi extremamente importante obter um mapa de distribuição populacional dos municípios para cruzar com outras variáveis que podem indicar as áreas susceptíveis à malária.

Para cada variável foi gerada uma grade de distância em metros, utilizando o Sprinng 3.6. Essas grades foram fatiadas, ou seja, para cada faixa de distância pré-determinada foi atribuída uma classe: muito-alta; alta; média; baixa e muito-baixa. Como por exemplo, para a distância da classe agrossilvopastoril foram determinadas as seguintes faixas de distância em relação à distribuição da população: muito-alta (de 0 a 99,999); alta (de 100 a 199,999); média (de 200 a 299,999); baixa (de 300 a 399,999) e muito-baixa $(\geq 400)$. Essas faixas foram determinadas por observações nas imagens de satélite e observações realizadas no trabalho de campo.

Após o fatiamento das grades de todas as variáveis, atribuíram-se valores para cada uma dessas classes com o objetivo de padronizá-las. Para a classe "muito-alta" foi atribuído o valor 3 , assim, todas as classes "muito-alta" de cada variável teriam o mesmo valor. Após essa padronização, se calculou uma média simples, somando-se todas as grades ponderadas e dividindo-se pelo número de variáveis analisa- 
das. O resultado obtido foi uma grade que representa o cruzamento de todas as variáveis para distribuição da população e outra grade com o cruzamento das variáveis para os mapas de risco de malária. Essas grades foram simplesmente fatiadas em muito-alta (de 3 a 2,24999); alta (de 2,24999 a 1,4999); média (de 1,4999 a $0,74999)$; baixa (de 0,74999 a 0,34999 ) e muitobaixa (de 0,34999 a 0).

Para utilizar a variável uso do solo foi necessário reclassificar as classes de acordo com o risco de malária que cada uma pode representar: vegetação nativa (risco muito baixo); rebrota (risco médio); água (risco muito baixo); agrossilvopastoril (risco muito alto); área alagada (risco alto); nuvem (risco muito baixo); banco de areia (risco muito baixo); área urbana (risco baixo); corte seletivo (risco alto).

\section{Resultados}

Em Jacundá, a área ocupada por atividades agrossilvopastoris, em 2001, foi quase duas vezes maior que a ocupada em 1996, ou seja, passou de $504,2 \mathrm{~km}^{2}$ para $972 \mathrm{~km}^{2}$. No período de cinco anos, este município perdeu o equivalente a $158,6 \mathrm{~km}^{2}$ de vegetação nativa ou $7,8 \%$ de sua área total. Se continuar no mesmo ritmo, toda a vegetação nativa desse município poderá desaparecer em aproximadamente 15 anos, dando lugar às pastagens e atividades madeireiras. Pôde-se observar também que grande parte das áreas que estavam em processo de regeneração em 1996 (mais de 45\%), passou a ser ocupada por atividades agrossilvopastoris em 200125 . Na Figura 1 encontram-se os mapas de uso e ocupação para os anos de 1996 e 2001.

Esse município, desde o início da década de 80, quando a barragem de Tucuruí começou a ser construída, sofreu um forte incremento populacional. Segundo dados de população do IBGE, em 1970, Jacundá tinha uma população de 2.225 habitantes e na década de 80 esse valor saltou para 14.868. A partir dessa época as áreas de floresta perderam espaço para assentamentos, abertura de estradas, projetos agropecuários, para a água do reservatório e para a ação dos madeireiros.

A segunda etapa da hidroelétrica de Tucuruí teve início em 2000 levando a novo aumento do fluxo de trabalhadores para a região. Até meados da década de 70, os níveis da doença eram baixos, mas em 1982 notificou-se próximo de 6 mil casos em Jacundá. As variações da incidência de malária nesse município podem ser observadas no gráfico da Figura 2.
Figura 1

Mapas de uso e ocupação do Município de Jacundá, Pará, Brasil, nos anos de 1996 e 2001.

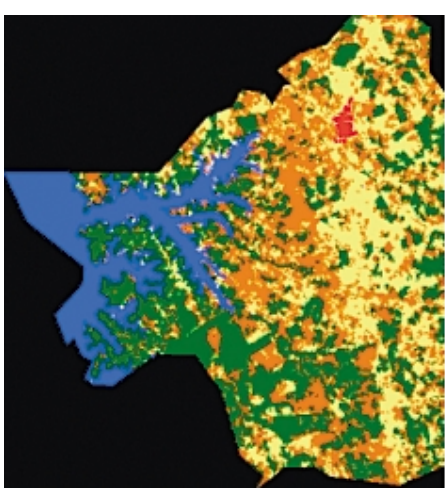

1996

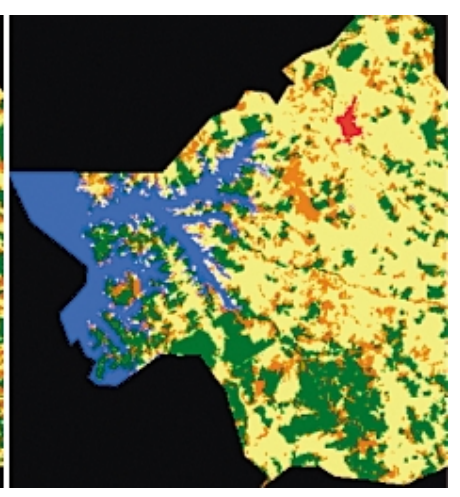

2001
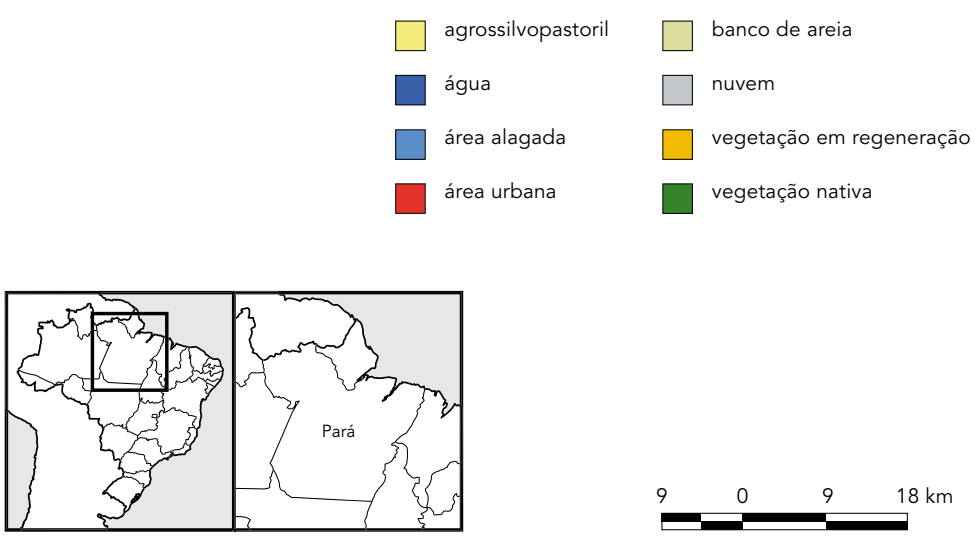

Observa-se no gráfico da Figura 3 que no Município de Jacundá a maior média de lâminas positivas ocorreu entre junho e outubro, nos meses de seca, marcando um padrão sazonal da malária.

No Município, apenas 20,1\% dos domicílios particulares permanentes possuem rede de água, enquanto os outros $80 \%$ utilizam poços, nascentes ou outras fontes (http://www.ibge.gov. br, acessado em 15/Jan/2004). Em conseqüência disso, as pessoas constroem suas casas próximas às margens de rios e igarapés. Foi observado que as áreas de maior concentração humana ocorreram nas margens das principais estradas e igarapés, estando coerente com o que foi observado no campo e pelas imagens de satélite. Na Figura 4 encontram-se os mapas de distribuição da população para os anos de 1996 e 2001. 
Figura 2

Casos de malária no Município de Jacundá, Pará, Brasil, entre os anos de 1962 e 1996.

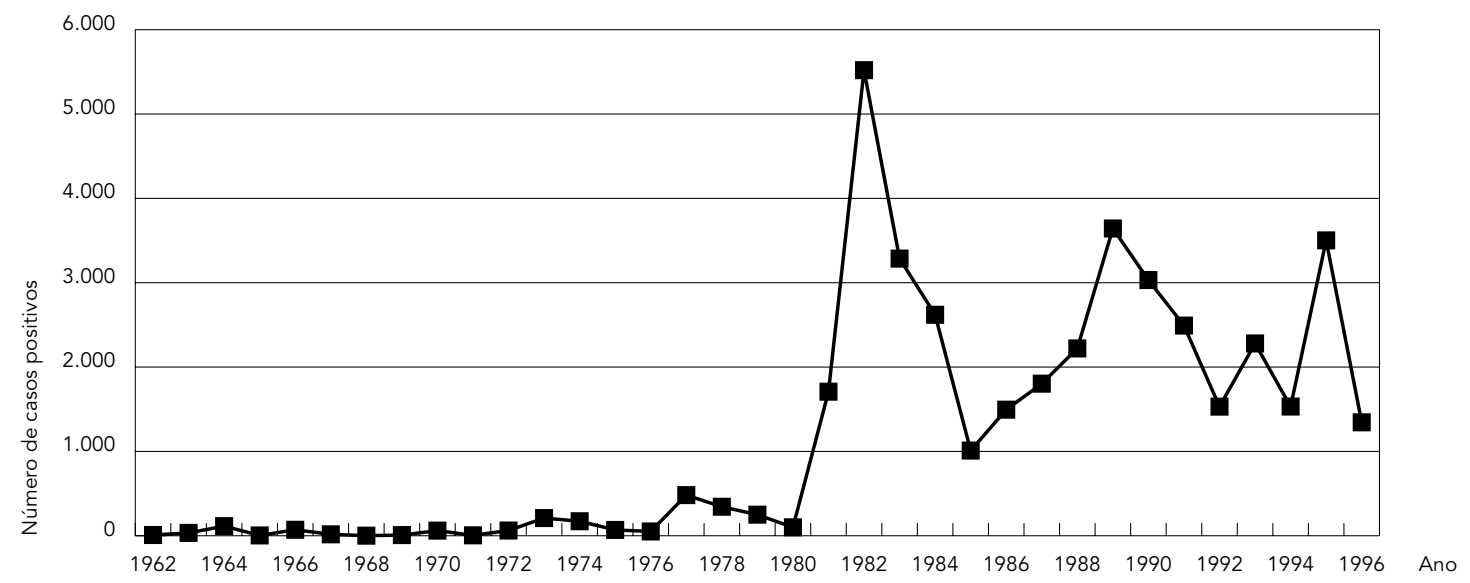

Figura 3

Lâminas positivas de malária no Município de Jacundá, Pará, Brasil, entre os anos de 1992 e 2002, versus a precipitação.

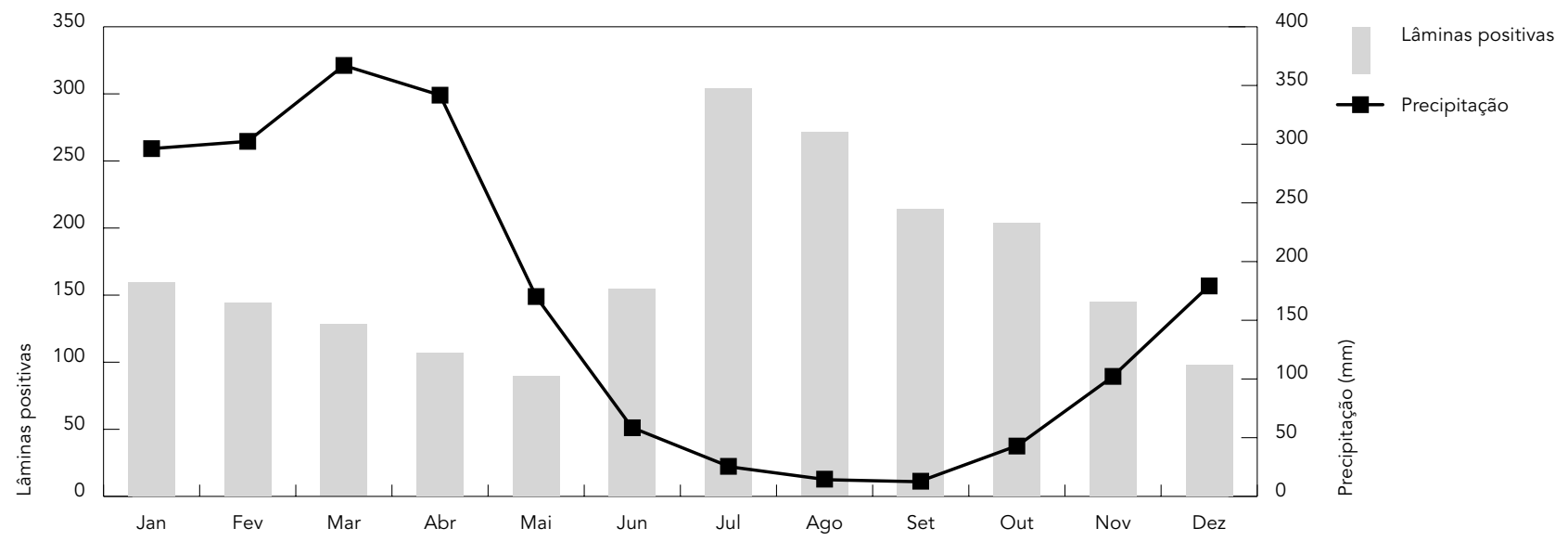


Pelo mapeamento realizado para a distribuição da população foi observado que nos arredores da sede municipal ocorreu maior concentração populacional, enquanto as áreas mapeadas com baixa concentração da população eram correspondentes às ocupadas por florestas. O único local com a classe "muito-alta" foi a sede do Município, onde se concentra a população urbana com 25.973 habitantes (http:// www.ibge.gov.br, acessado em 15/Jan/2004). Quando os resultados dos anos de 1996 e 2001 foram comparados, observou-se que na área rural não ocorreram modificações significativas, mas sim, no entorno da área urbana, onde a alteração foi mais perceptível, pois aumentou a área de maior aglomeração populacional. No período estudado ocorreu o êxodo rural segundo o Censo do IBGE de 2000, pois na área rural em 1996 havia 13.553 habitantes. Essa população caiu para apenas $6.028(44,4 \%)$ em 2001, enquanto a população urbana passou de 25.973 para 34.518 , ou seja, um incremento de $32,8 \%$ em apenas cinco anos. O mapeamento realizado detectou esse incremento populacional na periferia da área urbana.

Observa-se nos mapas da Figura 5 que as áreas mapeadas em Jacundá como susceptíveis à malária aumentaram entre 1996 e 2001, principalmente no entorno da sede municipal, coincidindo com áreas de alta concentração populacional. Os pontos georreferenciados no campo (26) são localidades onde ocorreram casos de malária nos últimos oito anos. Adotouse que cada ponto abrangeria uma área com raio de aproximadamente $1.500 \mathrm{~m}$, considerando o alcance aproximado de raio de vôo dos mosquitos do gênero Anopheles. Em Jacundá, para os anos de 1996 e 2001, aproximadamente $60,0 \%$ das localidades estavam em áreas de alto risco ou sob influência delas e os outros $40,0 \%$ em áreas de médio risco. O mapeamento realizado detectou áreas como de alto risco, coincidindo com áreas que apresentam altos valores de IPA, segundo a FUNASA. O número de casos de malária continuou elevado nos anos de 2001 e 2002. Em Jacundá, chegou a atingir mais de 800 casos em julho de 2002, em função das obras da segunda etapa da hidroelétrica de Tucuruí.

\section{Discussão}

O aumento do número de casos notificados no município a partir da década de 80 coincide com a implantação da barragem de Tucuruí. As áreas alteradas com a formação do lago são propícias para a proliferação de plantas aquá-
Figura 4

Mapas de distribuição da população no Município de Jacundá, Pará, Brasil, nos anos de 1996 e 2001.
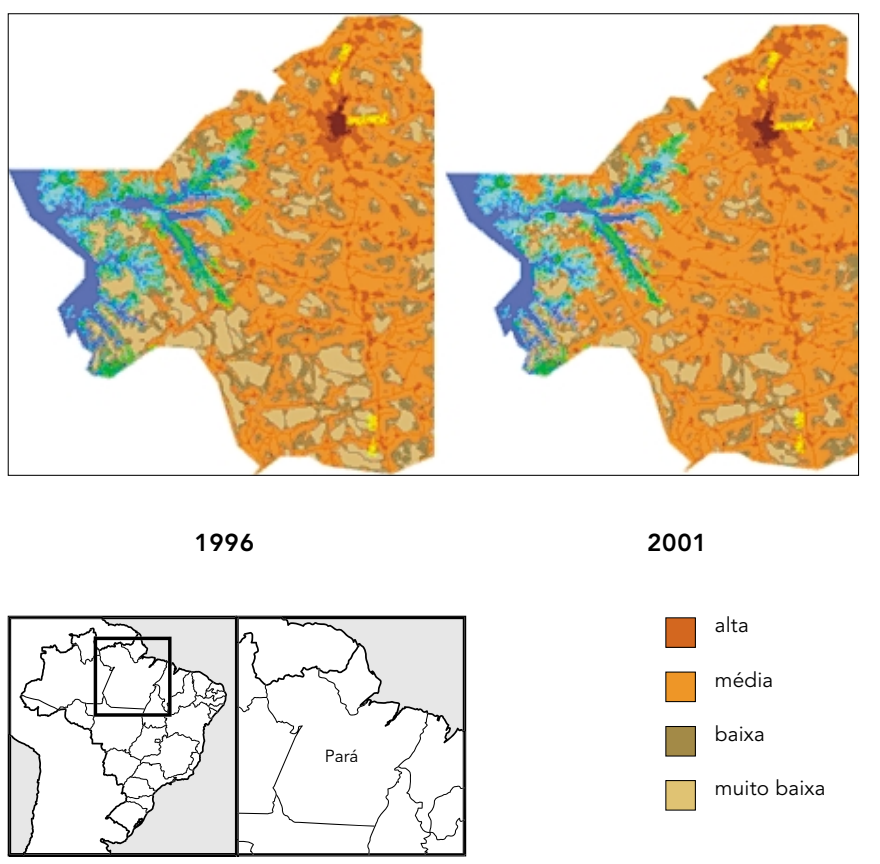

alta

$\square$ média

baixa

muito baixa

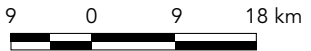

ticas, as quais possivelmente se tornaram ótimos criadouros de mosquitos 29 , relacionados com o aumento da densidade populacional dos anofelinos dessa região.

A sazonalidade dos casos pode ser explicada pelo fato de que, nesse mesmo período, se realiza a colheita das principais lavouras da região (arroz, milho e feijão). Um dos motivos para que esta atividade esteja relacionada ao aumento da malária, é que requer um aumento de trabalhadores no campo e estes, muitas vezes, permanecem durante alguns dias ou meses em habitações provisórias e precárias, ficando expostos aos vetores da doença. $\mathrm{Na}$ época de seca o reservatório encontra-se com cota máxima e isso altera o nível do lençol freático e dos igarapés da região. A conseqüência disso é o aumento de áreas propícias ao desenvolvimento de larvas dos mosquitos em áreas alagadiças nas partes mais baixas e nas proximidades de estradas. O reservatório permanece estabilizado com cota máxima por alguns meses e isso é bom para as larvas dos mosquitos porque para que elas se desenvolvam é necessário um criadouro estabilizado. Por ser o 
Figura 5

Mapas de áreas susceptíveis à malária no Município de Jacundá, Pará, Brasil, nos anos de 1996 e 2001.

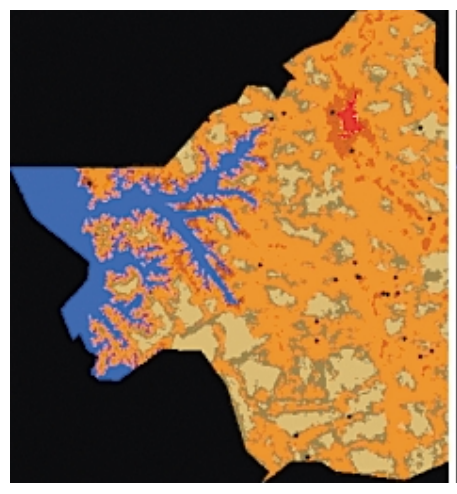

1996

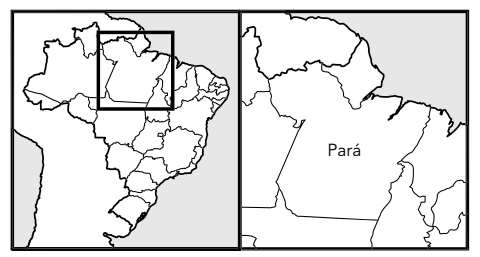

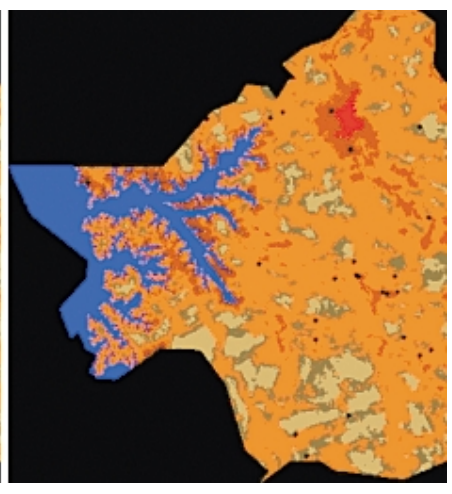

2001
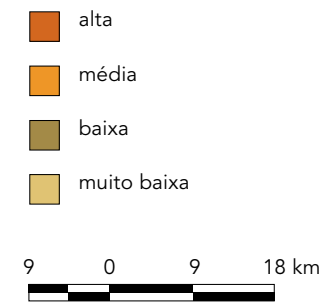

reservatório de padrão dendrítico, com muitas reentrâncias nas bordas, propicia a formação de plantas aquáticas em suas margens. Essas plantas funcionam como ótimos criadouros, pois protegem as larvas de predadores e reduzem a velocidade da água. Nos meses de chuva as comportas da usina são abertas e o reservatório se apresenta com cota mínima e com isso as plantas aquáticas que permanecem nas margens, entram em estado de senescência e morrem. O período da seca coincide também com o período das férias escolares, o que acarreta o aumento de pessoas nas propriedades rurais, principalmente de crianças. Outro fator é que nos meses de seca as pessoas aproveitam para sair mais de casa que nos meses de chuva, ficando mais expostas aos transmissores da malária.

A malária é uma doença que está muito ligada aos problemas sociais. A falta de infra-estrutura dos serviços de abastecimento de água e assistência médico sanitária, a precariedade das habitações, aliadas à grande mobilidade da população em áreas de risco, dificultam a atuação dos serviços de saúde para o controle e prevenção da doença.

Quando os resultados dos anos de 1996 e 2001 foram comparados, os mapas indicaram a expansão das áreas de risco e concentração no entorno da cidade.

O principal motivo para continuar ocorrendo alta incidência de malária a partir de 2000 é a construção da segunda etapa da Usina Hidroelétrica de Tucuruí, o que levou ao aumento de trabalhadores na região, principalmente migrantes, possivelmente susceptíveis à infecção. Essa etapa visa a aumentar a cota do reservatório em mais dois metros para aumentar a geração de energia e isso acarreta o aumento de áreas alagadas e conseqüentemente o aumento de criadouros dos mosquitos da malária.

\section{Conclusões}

A variação temporal e espacial da malária na região de estudo está relacionada com a operação do reservatório, desmatamento, a precipitação e com a dinâmica da população humana, isto é, com os padrões de ocupação da terra, abertura de estradas e de migração.

Apesar das ações de descentralização da assistência e controle da malária na região amazônica nos últimos anos, situações singulares como em áreas de grandes projetos de impacto ambiental são particularmente susceptíveis à transmissão da doença. Constituem-se rapidamente novas regiões epidêmicas em contraste com áreas mais estáveis, de ocupação antiga, onde se observa padrão hipoendêmico, com relativa estabilidade da transmissão. O desmatamento de áreas extensas, migrações, a formação de aglomerações desprotegidas e a falta de infra-estrutura são determinantes na ocorrência de epidemias.

As técnicas de sensoriamento remoto e os sistemas de informações geográficas podem contribuir no monitoramento de situações de risco, auxiliando as ações de controle da endemia. São ferramentas propícias particularmente em regiões de evidente risco ambiental, onde ações específicas de proteção e assistência às populações mais vulneráveis podem ser priorizadas. 


\section{Resumo}

A construção da hidroelétrica de Tucuruí, no sudeste do Estado do Pará, Brasil, em 1981, impôs grandes mudanças ambientais, desmatamentos e migração para a região. O objetivo deste trabalho é verificar a influência destas mudanças na ocorrência da malária no Município de Jacundá, Pará, Brasil, utilizando-se técnicas de sensoriamento remoto e sistemas de informações geográficas. Os parâmetros utilizados para a construção dos mapas foram: distância das estradas, classe agrossilvopastoril, distância de coleções hídricas (rios, igarapés e do reservatório) e da área urbana do município. Neste estudo, verificou-se o caráter epidêmico da malária a partir da construção da barragem de Tucuruí. Sugere-se que o padrão sazonal da incidência está relacionado com o período de maior estabilidade das margens do reservatório e ocorrência de áreas alagadas, além de maior exposição de trabalhadores na época de colheita na região. Foi observado que a distribuição dos casos está relacionada com as formas de uso e ocupação da terra, principalmente em áreas de maior influência das estradas, locais onde se concentra grande parte da população.

Malária; Central Hidrelétrica; Alteração Ambiental; Sensores Remotos

\section{Colaboradores}

C. H. Vasconcelos foi a principal responsável pela realização da pesquisa. E. M. L. M. Novo foi responsável pela orientação e revisão do trabalho. M. R. Donalisio participou da revisão do trabalho.

\section{Agradecimentos}

À FAPESP (Fundação de Amparo à Pesquisa no Estado de São Paulo) pelo financiamento do projeto de Doutorado (processo 01/07693-4), ao CNPq (Conselho Nacional de Desenvolvimento Científico e Tecnológico) pela bolsa DTI (Desenvolvimento Tecnológico Industrial) concedida ao Projeto Saudável (processo 552044/2002-4), ao INPE (Instituto Nacional de Pesquisas Espaciais) pela infra-estrutura cedida para o desenvolvimento do trabalho, à ELETRONORTE (Centrais Elétricas do Norte S.A.) e aos funcionários da Fundação Nacional de Saúde do Município de Jacundá pelo apoio de campo.

\section{Referências}

1. Wood CH. Land use and deforestation in the Amazon. In: Wood CH, Porro R, editors. Deforestation and land use in the Amazon. Gainesville: University Press of Florida; 2002. p. 1-38.

2. Cochrane M, Alencar A, Schulze M, Souza C, Lefebvre P, Nepstad D. Investigating positive feedbacks in the fire dynamic of closed canopy tropical forests. In: Wood CH, Porro R, editors. Deforestation and land use in the Amazon. Gainesville: University Press of Florida; 2002. p. 285-98.

3. Nepstad D, Carvalho G, Barros AC, Alencar A, Capobianco JP, Bishop J, et al. Road paving, fire regime feedbacks, and the future of Amazon forests. For Ecol Manage 2001; 154:395-407.

4. Nobre C. Amazônia e clima. In: Pavan C, organizador. Uma estratégia latino-americana para a Amazônia 2. Brasília: Ministério do Meio Ambiente dos Recursos Hídricos e da Amazônia Legal; 1996. p. 99-109.

5. Nobre C, Sellers P, Shukla J. Amazonian deforestation and regional climate change. J Clim 1991; 4:957-88.

6. Laurance WF, Cochrane MA, Bergen S, Fearnside PM, Delamônica P, Barber C, et al. The future of the Brazilian Amazon. Science 2001; 291:438-9.

7. Massad E, Forattini PO. Modelling the temperature sensitivity of some physiological parameters of epidemiologic significance. Ecosyst Health 1998; 4:119-29.

8. McMichael JA, Patz J, Kovats RS. Impacts of global environmental change on future health and health care in tropical countries. Br Med Bull 1998; 2:475-88.

9. McCracken SD, Siqueira AD, Moran EF, Brondízio ES. Land use patterns on an agricultural frontier in Brazil. In: Wood CH, Porro R, editors. Deforestation and land use in the Amazon. Gainesville: University Press of Florida; 2002. p. 162-92.

10. Barros M. A questão da saúde na Amazônia. In: Pavan C, organizador. Uma estratégia latino-americana para a Amazônia 2. Brasília: Ministério do Meio Ambiente dos Recursos Hídricos e da Amazônia Legal; 1996. p. 315-23.

11. Marques AC, Pinheiro EA. Fluxos de casos de malária no Brasil em 1980. Rev Bras Malariol Doencas Trop 1982; 34:1-31.

12. Sawyer DR. Malaria on the Amazon frontier: economic and social aspects of transmission and control. Geneva: World Health Organization; 1992. (Technical Report on Malaria Control in the Amazon Basin, 88).

13. Tauil PL. Malária: agrava-se o quadro da doença no Brasil. Ciênc Hoje 1984; 2:58-66.

14. Loiola CCP, Silva CJM, Tauil PL. Controle da malária no Brasil: 1965 a 2001. Rev Panam Salud Publica 2002; 11:235-44.

15. Camargo LMA, Ferreira UM, Krieger H, Camargo EP, Silva LP. Unstable hypoendemic malaria in Rondônia (Western Amazon Region Brazil): epidemic outbreaks and work associated incidence in an agro-industrial rural settlement. Am J Trop Med Hyg 1994; 51:16-25.

16. Junk WJ. Os recursos hídricos da Amazônia. In: Pavan C, organizador. Uma estratégia latino-ame- 
ricana para a Amazônia 2. Brasília: Ministério do Meio Ambiente dos Recursos Hídricos e da Amazônia Legal; 1996. p. 247-59.

17. Thomson MC, Connor SJ, Milligan PJM, Flasse SP. Mapping malaria risk in Africa: what can satellite data contribute? Parasitol Today 1997; 13:313-8.

18. Hugh-Jones ME. Applications or remote sensing to the identification of habitats of parasites and disease vectors. Parasitol Today 1989; 5:244-51.

19. Pope KO, Rejmankova E, Savage HM, ArredondoJimenez JI, Rodriguez MH. Remote sensing of tropical wetlands for malaria control in Chiapas, Mexico. Ecological Applications 1994; 4:81-90.

20. Thomson RA, Lima JWO, Maguire JH, Brand DH, School DT. Climatic and demographic determinants of American Visceral Leishmaniasis in Northeastern Brazil using remote sensing technology for environmental characterization of rain and region influences on leishmaniasis. Am J Trop Med Hyg 2002; 67:648-55.

21. Crosta AP. Processamento digital de imagens de sensoriamento remoto. Campinas: Editora Unicamp; 1992.

22. Shimabukuro YE, Smith JA. The least-squares mixing models to generate fraction images derived from remote sensing multispectral data. IEEE Transactions on Geoscience and Remote Sensing 1991; 29:16-20.

23. Hussain Z. Digital image processing: practical applications of parallel processing techniques. New York: Ellis Horwood; 1991.

24. Mather PM. Computer processing of remotelysensed images. Chichester: Jonh Wiley \& Sons; 1999.
25. Vasconcelos CH, Novo EMLM. Mapeamento do uso e cobertura da terra a partir da segmentação e classificação de imagens - fração solo, sombra e vegetação derivadas do modelo linear de mistura aplicado a dados do sensor TM/Landsat5, na região do reservatório de Tucuruí - PA. Acta Amazônica 2004; 34:487-93.

26. Barbosa CF. Álgebra de mapas e suas aplicações em sensoriamento remoto e geoprocessamento [Dissertação de Mestrado]. São José dos Campos: Instituto Nacional de Pesquisas Espaciais; 1999.

27. Bonham-Carter GF. Geographical information systems for geoscientists: modelling with GIS. New York: Computer Methods in the Geosciences; 1996.

28. Kampel AS. Geoinformação para estudos demográficos: representação espacial de dados de população na Amazônia brasileira [Tese de Doutorado]. São Paulo: Escola Politécnica, Universidade de São Paulo; 2004.

29. Tadei WP, Santos JMM, Scarpassa VM, Rodrigues IB. Incidência, distribuição e aspectos ecológicos de espécies de Anopheles (Diptera: Culicidae), em regiões naturais e sob impacto ambiental da Amazônia brasileira. In: Ferreira EJG, Santos GM, Leão ELM, Oliveira ELM, organizadores. Bases científicas para estratégia de preservação e desenvolvimento da Amazônia 2. Manaus: Instituto Nacional de Pesquisas da Amazônia; 1993. p. 167-96.

Recebido em 24/Jan/2005

Versão final reapresentada em 21/Mai/2005 Aprovado em 06/Jun/2005 